\title{
Diagnosa Hama dan Penyakit pada Tanaman Jeruk dengan Menerapkan Jaringan Syaraf Tiruan Learning Vector Quantization (Studi Kasus : Badan Penyuluhan Pertanian Kuok)
}

\author{
Megawati $^{1}$, Reski Mai Candra ${ }^{2}$ \\ 1,2Teknik Informatika UIN Sultan Syarif Kasim Riau \\ Jl. H.R. Soebrantas no. 155 KM. 18 Simpang Baru, Pekanbaru 28293 \\ acik_mega@yahoo.com ${ }^{1}$, reski.candra@uin-suska.ac.id ${ }^{2}$
}

\begin{abstract}
Abstrak - Jeruk siam termasuk salah satu jenis jeruk mandarin yang sudah cukup dikenal banyak orang. Tanaman jeruk ini banyak dijumpai di daerah tropis. Tiga bulan terakhir tahun 2014sebagian besar kebun jeruk di Kabupaten kampar diserang berbagai jenis hama dan penyakit sehingga mengakibatkan produktivitas dari tanaman jeruk tersebut menurun. Serangan hama dan penyakit ini membuat para petani kebingungan untuk menghadapi masalah perkebunan mereka, sebagian dari mereka tidak mengetahui jenis hama dan penyakit apa yang menyerang kebun jeruk mereka. Hama penyakit yang menyerang tanaman jeruk siam ini sangat bervariasi sehingga sering terjadi kesalahan dalam memberikan solusi terhadap tanaman yang sudah terserang hama. Diagnosa hama dan penyakit pada tanaman jeruk dengan metode Jaringan Syaraf Tiruan (JST) Learning Vector Quantization (LVQ) dapat memberikan jenis hama dan penyakit pada tanaman jeruk dan bagaimana solusi/pengendalian yang harus dilakukan berdasarkan gejala-gejala hama dan penyakit yang ada pada tanaman jeruk. Gejala yang ada pada hama ada 21 gejala sedangkan untuk penyakit ada 34 gejala. Setelah melalui proses pembelajaran dan pengujian pada data-data gejala yang telah dientrikan maka sistem akan mengklasifikasi kesesuaian jenis hama dan penyakit dalam 12 kategori kelas untuk hama dan 17 kategori kelas untuk penyakit. Berdasarkan pengujian parameter yang dilakukan bila dipersentasekan hasil akurasi pengujian LVQ adalah mencapai $93.10 \%$.
\end{abstract}

Kata Kunci - LVQ, diagnosa hama dan penyakit jeruk, JST

\section{PENDAHULUAN}

Jeruk sampai saat ini masih merupakan komoditas buah yang menguntungkan untuk diusahakan. Namun produktivitas jeruk di indonesia mengalami penurunan yang cukup drastis. Pada tahun 1995, produktivitas jeruk dapat mencapai 21 ton/ha tetapi pada tahun 1999 menjadi 17 ton/ha. Dengan pengembangan rehabilitasi sentra-sentra tanaman baru, pada tahun 2000 terjadi peningkatan produksi peningkatan 644.052 ton tetapi jumlah itu hanya setengah dari kebutuhan dalam negeri yang mencapai hampir 1,2 juta ton $(5,1 \mathrm{~kg} /$ tahun per kapita)[1]. Jeruk adalah salah satu hasil mata pencarian dan juga sebagai penunjang perekonomian rumah tangga mereka yang dibudidayakan masyarakat petani dikecamatan Kuok terutama didesa Pulau Belimbing. Tiga bulan terakhir tahun 2014 ini sebagian besar kebun jeruk di Kabupaten kampar diserang berbagai jenis hama dan penyakit sehingga mengakibatkan produktivitas dari tanaman jeruk tersebut menurun. Serangan hama dan penyakit ini membuat para petani kebingungan untuk menghadapi masalah perkebunan mereka, sebagian dari mereka tidak mengetahui jenis hama dan penyakit apa yang menyerang kebun jeruk mereka dan juga tidak mengetahui solusi/ pengendalian apa yang harus mereka lakukan. akibat serangan hama ini ribuan ton buah jeruk busuk dan gugur ke tanah, sehingga membuat para petani mengalami kerugian yang cukup besar.

Usaha manusia dalam mengembangkan suatu sistem yang meniru kemampuan dan perilaku makhluk hidup telah berlangsung selama beberapa decade belakangan ini. Jaringan saraf tiruan (JST), merupakan hasil perkembangan ilmu dan teknologi yang kini sedang berkembang pesat. JST yang berupa susunan sel-sel saraf tiruan (neuron) dibangun berdasarkan prinsip-prinsip organisasi otak manusia. Perhatian yang besar pada JST disebabkan adanya keunggulan yang dimilikinya seperti kemampuan untuk belajar, dan Komputasi paralel. Adapun beberapa metode yang biasa diterapkan dalam jaringan syaraf tiruan adalah : backpropagation, Learning vector quantization (LVQ), hopfield, ADALINE dan lain sebagainya. Learning vector quantization (LVQ) adalah adalah suatu metode untuk melakukan pembelajaran pada lapisan kompetitif yang terawasi.

Suatu lapisan kompetitif akan secara otomatis belajar untuk mengklasifikasikan vektorvektor input. Kelas-kelas yang didapatkan sebagai hasil dari lapisan kompetitif ini hanya tergantung pada jarak antara vektor-vektor input. Jika dua vektor input mendekati sama, maka lapisan kompetitif akan meletakkan kedua vektor input tersebut kedalam kelas yang sama. 


\section{LEARNING VECTOR QUANTIZATION}

Learning Vector Quantization ( $L V Q)$ adalah suatu metode untuk melakukan pembelajaran pada lapisan kompetitif yang terawasi. Suatu lapisan akan secara otomatis belajar untuk mengklasifikasikan vektor-vektor input. Kelas-kelas yang didapatkan sebagai hasil dari lapisan kompetitif ini hanya tergantung pada jarak antara vektor-vektor input. Jika ada 2 vektor input mendekati sama, maka lapisan kompetitif akan meletakkan kedua vektor input tersebut kedalam kelas yang sama[3]. Gambar 1.

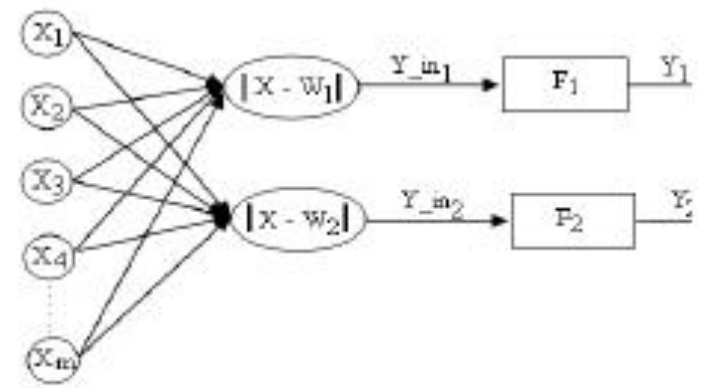

Gambar 1. Arsitektur LVQ

\section{HAMA DAN PENYAKIT PADA TANAMAN}

Adapun hama jeruk antara lain[1]:

1. Kutu Loncat Jeruk

2. Kutu Daun Hijau, Coklat dan Hitam (Toxoptera citridicus,

3. Tungau Merah dan Tungau Karat (Panonycus citri,

4. Thrips(Scritothrips citri)

5. Ulat Peliang Daun (Phylocnistis citriella)

6. Kutu Sisik/Kutu Perisai (Lepidosaphes beckii, Unaspsis citri)

7. Puru Buah (Citripestis sagitiferella)

8. Lalat Buah (Batrocera spp)

9. Penggerak Buah

10. Kutu Dempolan (Planococcus citri)

11. Kumbang Pemakan Daun (Maleuterpes dentipes)

12. Ulat Daun

Adapun penyakit jeruk anatara lain[1]:

1. CVPD (citrus vein phloem degeneration)

2. Tristeza

3. Puru berkayu

4. Exocortis

5. Psorosis

6. Cachexia xyloporosis

7. Tatter leaf

8. Diplodia

9. Busuk Pangkal Batang

10. Rabah Kecambah

11. Antraknosa

12. Kudis
13. Jamur Upas

14. Embun Jelaga

15. Ganggang

16. Kanker

Pada penelitian ini akan menerapakan sebuah algoritma jaringan syaraf tiruan learning vector quantization untuk diagnosa hama dan penyakit pada tanaman jeruk dengan menerapkan sebuah jaringan LVQ yang memiliki 21 gejala masukan untuk hama dan 34 gejala masukan untuk penyakit pada tanaman jeruk. Sedangkan keluaran terdiri atas 12 kelas hama pada tanaman jeruk dan 17 kelas penyakit pada tanaman jeruk. Data yang digunakan sebagai input adalah kuisioner yang dibagikan kepada para pegawai (bagian pengamat hama dan penyuluhan) yang ada di Badan Penyuluhan Pertanian. Selanjutnya data masukan tersebut akan dilakukan proses pembelajaran untuk klasifikasi nama hama dan penyakit pada tanaman jeruk dengan algoritma LVQ.

Setelah data tersebut dilatih, akan diperoleh bobot-bobot akhir (W). Bobot-bobot ini nantinya akan digunakan untuk melakukan pengujian terhadap beberapa buah data uji sehingga diperoleh ketepatan hasil pengujian tersebut dengan target yang sebenarnya. maka dapat digambarkan arsitektur jaringan syaraf tiruan LVQ untuk hama yang ditunjukan pada Gambar 2.

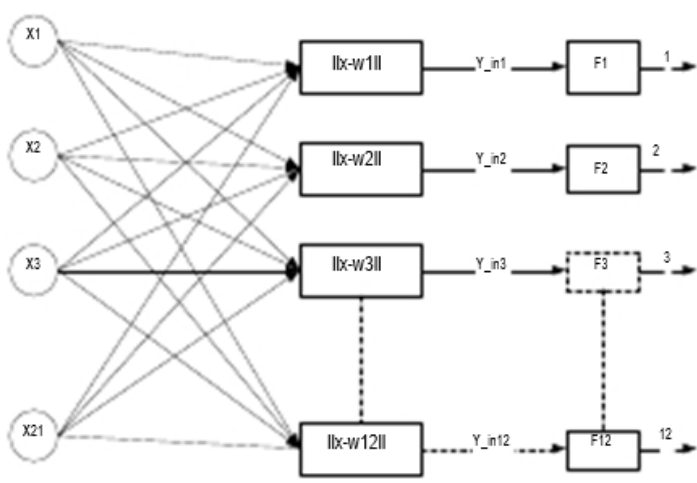

Gambar 2.Arsitektur LVQ hama

Arsitektur jaringan syaraf tiruan LVQ untuk penyakit yang ditunjukan pada Gambar 3 . 


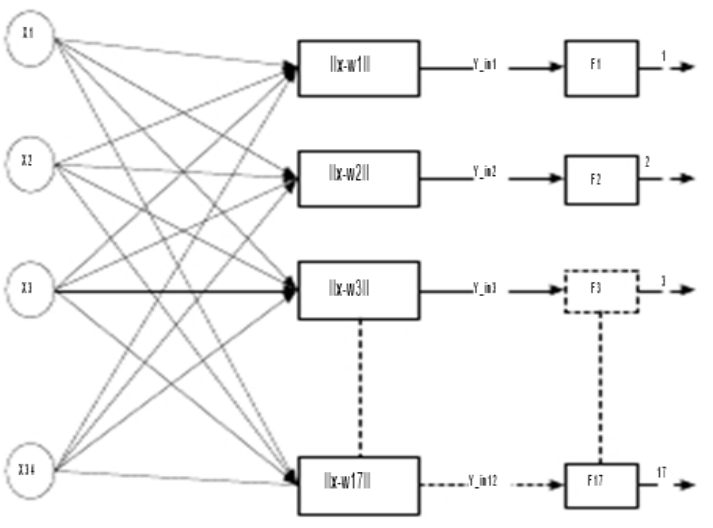

Gambar 3. Arsitektur LVQ penyakit

\section{HASIL DAN PEMBAHASAN}

Pengujian parameter ini kita harus menentukan parameter-parameter LVQ terlebih dahulu. Parameter-parameter yang digunakan adalah

1. Learning rate $(\alpha): 0.05-0.7$

2. Nilai minimal learning rate (Min a) : 0.01

3. Nilai pengurangan learning rate $: 0.1$

Hasil pengujian LVQ dapat dilihat pada Tabel 1.

Tabel 1. Pengujian hama

\begin{tabular}{|c|c|c|c|c|c|}
\hline \multirow{3}{*}{$\begin{array}{l}\text { Da } \\
\text { ta } \\
\text { ke- }\end{array}$} & \multicolumn{4}{|c|}{ Hasil Kelas Diagnosa Hama } & \multirow{3}{*}{$\begin{array}{l}\text { Tar } \\
\text { get }\end{array}$} \\
\hline & $\begin{array}{c}\text { learni } \\
\text { ng } \\
\text { rate } \\
(\alpha)= \\
0.05\end{array}$ & $\begin{array}{c}\text { learni } \\
\text { ng } \\
\text { rate } \\
(\alpha)= \\
0.075\end{array}$ & $\begin{array}{c}\text { learni } \\
\text { ng } \\
\text { rate } \\
(\alpha) \\
=0.1\end{array}$ & $\begin{array}{c}\text { learni } \\
\text { ng } \\
\text { rate } \\
(\alpha)= \\
0.7\end{array}$ & \\
\hline & $\begin{array}{c}\text { Berh } \\
\text { enti } \\
\text { pada } \\
\text { epoch } \\
\text { ke }= \\
16\end{array}$ & $\begin{array}{c}\text { Berh } \\
\text { enti } \\
\text { pada } \\
\text { epoch } \\
\text { ke }= \\
20\end{array}$ & $\begin{array}{c}\text { Berh } \\
\text { enti } \\
\text { pada } \\
\text { epoch } \\
\text { ke = } \\
22\end{array}$ & $\begin{array}{c}\text { Berh } \\
\text { enti } \\
\text { pada } \\
\text { epoch } \\
\text { ke = } \\
41\end{array}$ & \\
\hline 1 & 1 & 1 & 1 & 1 & 1 \\
\hline 2 & 2 & 2 & 2 & 2 & 2 \\
\hline 3 & 3 & 3 & 3 & 3 & 3 \\
\hline 4 & 4 & 4 & 4 & 4 & 4 \\
\hline 5 & 5 & 5 & 5 & 5 & 5 \\
\hline 6 & 6 & 6 & 6 & 6 & 6 \\
\hline 7 & 7 & 7 & 7 & 7 & 7 \\
\hline 8 & 8 & 8 & 8 & 8 & 8 \\
\hline 9 & 9 & 9 & 9 & 9 & 9 \\
\hline 10 & 10 & 10 & 10 & 10 & 10 \\
\hline 11 & 11 & 11 & 11 & 11 & 11 \\
\hline 12 & 12 & 12 & 12 & 12 & 12 \\
\hline
\end{tabular}

Tabel 2. Pengujian Penyakit

\begin{tabular}{|c|c|c|c|c|c|}
\hline \multirow{4}{*}{$\begin{array}{c}\text { Da } \\
\text { ta } \\
\text { ke- }\end{array}$} & \multicolumn{4}{|c|}{ Hasil Kelas Diagnosa Penyakit } & \multirow{4}{*}{$\begin{array}{l}\text { Tar } \\
\text { get }\end{array}$} \\
\hline & $\begin{array}{c}\text { learni } \\
\text { ng } \\
\text { rate } \\
(\alpha)= \\
0.05\end{array}$ & $\begin{array}{c}\text { learni } \\
\text { ng } \\
\text { rate } \\
(\alpha)= \\
0.075\end{array}$ & $\begin{array}{c}\text { learni } \\
\text { ng } \\
\text { rate } \\
(\alpha) \\
=0.1\end{array}$ & $\begin{array}{c}\text { learni } \\
\text { ng } \\
\text { rate } \\
(\alpha)= \\
0.7\end{array}$ & \\
\hline & $\begin{array}{c}\text { Berh } \\
\text { enti } \\
\text { pada } \\
\text { epoch }\end{array}$ & $\begin{array}{c}\text { Berh } \\
\text { enti } \\
\text { pada } \\
\text { epoch }\end{array}$ & $\begin{array}{c}\text { Berh } \\
\text { enti } \\
\text { pada } \\
\text { epoch }\end{array}$ & $\begin{array}{c}\text { Berh } \\
\text { enti } \\
\text { pada } \\
\text { epoch }\end{array}$ & \\
\hline & $\begin{array}{c}\mathrm{ke}= \\
16\end{array}$ & $\begin{array}{c}\mathrm{ke}= \\
20\end{array}$ & $\begin{array}{c}\mathrm{ke}= \\
22\end{array}$ & $\begin{array}{c}\mathrm{ke}= \\
41\end{array}$ & \\
\hline 1 & 1 & 1 & 1 & 1 & 1 \\
\hline 2 & 2 & 2 & 2 & 2 & 2 \\
\hline 3 & 3 & 3 & 3 & 3 & 3 \\
\hline 4 & 4 & 4 & 4 & 4 & 4 \\
\hline 5 & 5 & 5 & 5 & 5 & 5 \\
\hline 6 & 6 & 6 & 6 & 6 & 6 \\
\hline 7 & 7 & 7 & 7 & 7 & 7 \\
\hline 8 & 8 & 8 & 8 & 8 & 8 \\
\hline 9 & 9 & 9 & 9 & 9 & 9 \\
\hline 10 & 9 & 14 & 14 & 14 & 10 \\
\hline 11 & 11 & 11 & 11 & 11 & 11 \\
\hline 12 & 12 & 12 & 12 & 12 & 12 \\
\hline 13 & 13 & 13 & 13 & 13 & 13 \\
\hline 14 & 16 & 16 & 16 & 16 & 14 \\
\hline 15 & 15 & 15 & 15 & 15 & 15 \\
\hline 16 & 16 & 16 & 16 & 16 & 16 \\
\hline 17 & 17 & 17 & 17 & 17 & 17 \\
\hline
\end{tabular}

\section{KESIMPULAN DAN SARAN}

Berdasarkan dari hasil analisa, perancangan dan implementasi pada sistem ini, dapat diambil beberapa kesimpulan diantaranya adalah:

1. Metode learning vektor quantization dapat diterapkan untuk menentukan nama hama dan penyakit pada tanaman jeruk beserta pengendaliannya.

2. Berdasarkan hasil pengujian user acceptance test menyatakan bahwa sistem dapat memudahkan para pegawai di BPP Kuok untuk menentukan nama hama dan penyakit pada tanaman jeruk beserta pengendaliannya.

3. Berdasarkan hasil pengujian parameter menyatakan bahwa diagnosa hama dan penyakit pada tanaman jeruk dengan metode LVQ sesuai dengan yang diharapkan (target). Bila dipersentasekan hasil akurasi pengujiannya adalah $93.10 \%$. 


\section{DAFTAR PUSTAKA}

[1] Balai Penelitian Tanaman Jeruk Dan Buah Subtropika, (2013), "Pengenalan Dan Pengendalian Hama Dan Penyakit Tanaman Jeruk", Agro Inovasi.

[2] Rikki S.Alex., (2014), “Aplikasi Jaringan Syaraf Tiruan untuk Penentuan Konsentrasi Program Studi Bagi Calon Mahasiswa Baru STMIK BUDIDARMA MEDAN.

[3] Ramadona Amanu, M.Nasrun, Bambang Siswoyo., (2004), “Aplikasi Jaringan Syaraf Tiruan Untuk Mengenali Angka Dengan Metode Learning Vector Quantization, Universitas Komputer Indonesia Bandung.

[4] Budianita, Elvia., (2012) "Penerapan Learning Vector Quantization (LVQ) untuk Klasifikasi Status Gizi Anak".

[5] Ceria A. Alfa, Sri Suwarno, Umi Proboyekti., (2014), "Pengenalan Aksara Jawa Menggunakan Learning Vector Quantization (LVQ)", Universitas Kristen Duta Wacana.

[6] Fakhrurrifqi Muhammad, Retantyo Wardoyo., (2013), "Perbandingan Algoritma Nearest Neighbour, C4.5 dan LVQ untuk Klasifikasi Kemampuan Mahasiswa”, FMIPA UGM, IJCCS, Vol.7, No.2, pp. 145154, ISSN: 1978-1520.

[7] Hidayati Nurul, Budi Warsito., (2010), "Prediksi terjangkitnya penyakit jantung Dengan metode learning vector quantization", FMIPA UNDIP, Media Statistika, Vol. 3, No. 1: 21-30.

[8] Itje Sela Enny, sri hartati, (2005) "Pengenalan Jenis Penyakit THT Menggunakan Jaringan Learning Vector Quantization" STMIK AKAKOM, Universitas Gadjah Mada.

[9] Kristanti Tanti, Theopilus Sitepu, (2013), "sistem pakar hama dan penyakit pada tanaman jeruk manis di kabupaten karo", jurusan S1 teknik informatika, fakultas teknologi informasi, universitas kristen maranatha, seminar nasional sistem informasi indonesia.

[10] Lestari Uning, (2012), "Sistem Aplikasi Identifikasi Lahan Untuk Budidaya Tanaman Pangan Menggunakan Learning Vector Quantization (LVQ)", Prosiding Seminar Nasional Aplikasi Sains \& Teknologi (SNAST) Periode III ISSN: 1979-911X Yogyakarta. 